NBER WORKING PAPER SERIES

\title{
ENVIRONMENTAL PREFERENCES AND TECHNOLOGICAL CHOICES: IS MARKET COMPETITION CLEAN OR DIRTY?
}

\author{
Philippe Aghion \\ Roland Bénabou \\ Ralf Martin \\ Alexandra Roulet \\ Working Paper 26921 \\ http://www.nber.org/papers/w26921
NATIONAL BUREAU OF ECONOMIC RESEARCH
1050 Massachusetts Avenue
Cambridge, MA 02138
April 2020

\begin{abstract}
We are thankful for valuable comments and suggestions from participants in the Institutions, Organizations and Growth (IOG) group at the Canadian Institute for advanced Research, at the EBRD Conference on "Environmental Economics and the Green Transition" and at the TSE workshop on "Markets, Morality and Social Responsibility". Léo Aparisi de Lannoy provided superb research assistance. Aghion and Bénabou gratefully acknowledge financial support from the Canadian Institute for Advanced Study. The views expressed herein are those of the authors and do not necessarily reflect the views of the National Bureau of Economic Research.
\end{abstract}

NBER working papers are circulated for discussion and comment purposes. They have not been peer-reviewed or been subject to the review by the NBER Board of Directors that accompanies official NBER publications.

(C) 2020 by Philippe Aghion, Roland Bénabou, Ralf Martin, and Alexandra Roulet. All rights reserved. Short sections of text, not to exceed two paragraphs, may be quoted without explicit permission provided that full credit, including (C) notice, is given to the source. 
Environmental Preferences and Technological Choices: Is Market Competition Clean or Dirty? Philippe Aghion, Roland Bénabou, Ralf Martin, and Alexandra Roulet

NBER Working Paper No. 26921

April 2020

JEL No. D21,D22,D62,D64,H23,O3,O31

\section{$\underline{\text { ABSTRACT }}$}

This paper investigates the joint effect of consumers' environmental concerns and product-market competition on firms' decisions whether to innovate "clean" or "dirty". We first develop a stepby-step innovation model to capture the basic intuition that socially responsible consumers induce firms to escape competition by pursuing greener innovations. To test and quantify the theory, we bring together patent data, survey data on environmental values, and competition measures. Using a panel of 8,562 firms from the automobile sector that patented in 42 countries between 1998 and 2012, we indeed find that greater exposure to environmental attitudes has a significant positive effect on the probability for a firm to innovate in the clean direction, and all the more so the higher the degree of product market competition. Results suggest that the combination of historically realistic increases in prosocial attitudes and product market competition can have the same effect on green innovation as major increase in fuel prices.

Philippe Aghion

College de France

3 Rue D'Ulm

75005 Paris

FRANCE

paghion@fas.harvard.edu

Roland Bénabou

Department of Economics

and Woodrow Wilson School

Princeton University

Princeton, NJ 08544

and NBER

rbenabou@princeton.edu

\author{
Ralf Martin \\ Imperial College Business School \\ London School of Economics \\ London SW7 2AZ \\ United Kingdom \\ and Centre for Economic Performance, LSE \\ r.martin@imperial.ac.uk
}

\author{
Alexandra Roulet \\ Insead \\ Boulevard de Constance \\ 77300 Fontainebleau, France \\ France \\ alexandra.roulet@insead.edu
}




\section{Introduction}

Should private firms get involved in mitigating climate change and other environmental problems? A traditional view against such corporate activism (Friedman 1970) is that firms should concentrate on achieving their economic objectives -starting with profit maximization - and let governments and/or markets, through regulations and contracts, deal with the associated externalities. In practice, however, we often see governments dragging their feet or being ineffective when it comes to implementing policies that effectively address environmental problems. Bénabou and Tirole (2010) discuss both the sources of these limitations (capture by interest groups, territoriality of jurisdiction, transaction and information costs) and how, together with prosocial and image motivations, they create a scope for individual and corporate "social responsibility".

A case in point is that of carbon taxes, which no single government has a strong incentive to implement since climate is a global issue, and which are often unpopular even with electorates that otherwise proclaim their "greenness". In France, for instance, the "yellow vests" movement was triggered by a modest increase in fuel and gasoline taxes. It then falls upon intrinsically motivated consumers, investors and firms to "do their part" through other channels, with reputationally motivated ones following suit. Similar trends are at work with the rise of "sustainable" and "fair trade" products, "ethical" investment funds, and the like.

Our focus in this paper is on firms' incentives to "innovate clean", and on the extent to which citizen's environmental concerns can be effective in shaping investment decisions 11 We argue, both theoretically and empirically, that product-market competition amplifies firms' response to citizens' demand for greater social responsibility, and that this complementarity has important consequences. Intuitively, firms will pursue greener innovations when facing more environmentally motivated customers, and the more so, the harder they have to compete for them.

The standard, static effect of greater product-market competition is to increases consumer surplus, by reducing (quality-adjusted) prices. From a dynamic point of view, it can also encourage innovation by firms, as a means to try and escape price competition

\footnotetext{
${ }^{1}$ Citizens could also directly contribute to environmental NGO's, but it may be more efficient to "delegate" some of their socially responsible preferences to firms, who have knowledge to directly affect outcomes. Moreover, enhancing one's social image may be more effectively achieved through the choice of consumption items (e.g., by purchasing greener cars) than through writing checks to charitable causes: the latter tends to be less visible except for the very rich, who make huge and well-publicized donations.
} 
(Aghion et al., 2001; Aghion et al., 2005). The novelty of the paper is to introduce both environmental externalities and social-responsibility concerns over them into the analysis. While the direct impact of competition on the environment is always negative - lower prices induce more mass consumption and therefore more pollution ${ }^{2}-$ the dynamic incentive can mitigate and even reverse it. Indeed, what matters here is not so much the effect of competition on the level of innovation, but rather how it affects its direction, namely the extent to which firms' R\&D and product mixes become more, or less, environmentally friendly.

In the first part of the paper, we develop a simple step-by-step innovation model with green innovation. The economy is populated by representative agents who care about both the level and the environmental "footprint" of their own consumption bundle. There is a continuum of differentiated goods, such as cars, appliances, etc., and the production and/or consumption of each unit generates a certain amount of pollution, determined by the technology embodied in the good by its producer. Producing cleaner goods, or producing more cleanly, requires green innovation and therefore adequate R\&D investments. We then analyze how consumers' environmental-responsibility concerns and the degree of competition between firms combine to shape: (i) the equilibrium amount of clean $R \& D$, and hence the kinds of goods consumed; (ii) total emissions or externalities; (iii) ultimately, net social welfare. While more competitive markets tend to worsen pollution by forcing down prices and raising output, they also induce more firms to innovate green, in order to escape direct price competition with their rivals. Due to these offsetting quantity and quality effects, the impact of competition on total emissions is shown to have a hump-shaped profile that we fully characterize, identifying in particular the conditions under which high versus low competition is pollution-minimizing. We furthermore show that social responsibility and competition have complementary effects in spurring green innovation, and that this positive interaction is also reflected in the equilibrium-emissions profile, which becomes more "competition friendly" (or, less unfriendly) as consumers' environmental concerns intensify.

In the second part of the paper, we bring together patent data, survey data on environmental values, and competition measures to test empirically the model's key com-

\footnotetext{
${ }^{2}$ The examples of China or India today, or of the increasing market share of SUV everywhere since the 1980s, are quite illustrative in that respect. Another example is increasing worldwide competition in the airline industry, resulting in increasing travel and emissions.
} 
parative statics. We relate the extent to which firms innovate in a clean direction to firm-specific measures of exposure to pro-environmental attitudes and competition. Our data covers 8,562 firms and 42 countries during the two periods of 1998-2002 and 2008-2012, with around 100,000 patents filed in the first period and 150,000 in the second one. A firm's exposure is defined as a weighted average of country-level measures of the corresponding variable, where the weights proxy for the importance of the various countries to the firm. For competition, we also construct and use a firm-level, Lerner-index-type measure of competition, but we can only do this for a sub-sample of firms. We follow Aghion et al. (2016) in two respects: first, we focus primarily on the automobile sector, where the distinction between clean and dirty patents is both easy to make and highly relevant; second, the weights mentioned above are computed using the firm's patenting activity between 1950 and 1995, i.e. before our period of analysis. This is based on the assumption that firms are more likely to take out patent protection in a particular market the more that market is important to them. We also check robustness to alternative weights definition. Our main findings are that pro-environment attitudes have a significant positive effect on the probability for a firm to patent more in the clean direction and that this is effect is stronger the higher competition is. In particular, our empirical analysis suggests that the combination of realistic increases in prosocial attitudes and in product market competition can have the same effect on green innovation as an $40 \%$ increase in fuel prices worldwide.

Our research relates to several strands of literature. The first one is the literature on competition and innovation (e.g. see Aghion, Harris and Vickers, 1997; Aghion et al, 2001; Aghion et al, 2005; Vives, 2008). We contribute to this literature by bringing environmental externalities and social responsibility concerns, and by analyzing how the latter interact with product market competition. Second, is the literature on growth and the environment pioneered by Nordhaus (1994) $]^{3}$. Most relevant here is the work on endogenous directed technical change and the environment (e.g. Newell, Jaffe and Stavins, 1999; Popp 2002; Acemoglu et al., 2012, Aghion et al., 2016) that analyzes how firms' incentives to invest in green innovation are shaped by public policy, such as carbon taxes and/or subsidies to green innovation. Our paper brings in individuals' willingness to "do their part" through their own consumption choices, which becomes essential when such policy-making is deficient. Third, there is the literature on individual and corporate social responsibility, which both arise from a mix of intrinsic

\footnotetext{
${ }^{3}$ See also Nordhaus (2002), Stern (2007) and Weitzman (2007, 2009),
} 
and reputational motivations (e.g., Bénabou and Tirole 2010, 2011; Hart and Zingales 2019 and many references in these papers). We contribute to this literature, both theoretically and empirically, by introducing product market competition as a channel through which consumers' social preferences can influence firms' investment decisions. This also relates our paper to experiments such as Falk and Szech (2013) and especially Bartling et al. (2015), where lab subjects compete in the roles of both consumers and producers.

The paper is organized as follows. Section 2 develops the theoretical analysis. Section 3 discusses the empirical strategy and data sources. Section 4 presents the empirical results. Section 5 concludes.

\section{Basic model}

In this section, we develop a step-by-step innovation model with environmental innovations. Time is discrete, with both individuals and firms living for one period. At the beginning of each period $t$, firms choose R\&D investments (e.g., hiring researchers), aiming to innovate and thereby maximize their expected end-of-period profits. Once innovations have realized, firms produce with their respective technologies, competing for consumers who care about both the prices and the environmental impact of the goods they buy. Revenues are paid out as wages to production and R\&D workers, and net profits are redistributed to consumers, who are also the firms' shareholders.

\subsection{Preferences}

There is a continuum of differentiated good, such as cars and trucks of various designs, appliances, etc., indexed by $j \in[0,1]$. Within and/or across these sectors, firms potentially differ both by the price they charge and the environmental (un)friendliness of the goods they produce. The production or consumption of one unit of good with environmental quality $q$ thus generates $x=1 / q$ units of emissions, or similar negative externality.

The economy is populated by representative agents with standard taste-for-variety preferences, but who are also concerned about their environmental "footprint". Specifically, we assume that an agent who buys $y_{j, f}$ units of quality $q_{j, f}$ from each firm $f$ 
producing in sector $j$ (denote that set as $F_{j}$ ) has consumption utility

$$
U_{t}=\int_{0}^{1} \ln \bar{y}_{j t} d j,
$$

where

$$
\bar{y}_{j}=\int_{f \in F_{j}} y_{j, f}\left(q_{j, f}\right)^{\delta} d f
$$

is the individual's "ethically-adjusted," or emissions-impact discounted, consumption of variety $j$. A few remarks are useful here.

First, these preferences embody a form of ethical motivation. An individual's contribution to aggregate emissions is negligible, and in particular does not affect the quality of the air (say) that he breathes; nonetheless, he intrinsically dislikes contributing to the externality. He feels guilty, or/and socially embarrassed, about the carbon he emits when driving or flying, and conversely is willing to pay a "virtue" premium for cleaner goods. The parameter $\delta$ captures the extent of these social-responsibility concerns.

Second, while sectors are imperfect substitutes, within each of them firms' qualityadjusted offerings are perfect substitutes. Therefore, all demand for a variety $j$ will go to the firm(s) in $F_{j}$ with the highest price/quality ratio, $q / p$. Furthermore, the logarithmic form of preferences implies that, in equilibrium, the same amount will be spent by consumers on each variety 4 . we normalize it to 1 , by choosing current expenditure as the numeraire $\mathrm{5}^{5}$

Finally, (1) represents only the part of consumers' utility that results from their consumption choices. The disutility suffered from total emissions will come in subtraction when analyzing welfare, but is taken by each individual as given.

\subsection{Technology and market structure}

Labor is the only input, with agents offering an infinitely elastic supply of it at a given wage, normalized to 1 . It takes $c$ units of labor to produce one unit of output (e.g., one car), with the firms' current technology determining the associated emissions, $1 / q$. The firm's technological level, in turn, reflects the cumulative number of (green) innovations

\footnotetext{
${ }^{4}$ To see this, note that a consumer will choose the $y_{j}$ 's to maximize $u=\int \ln y_{j} d j$ subject to the budget constraint $\int p_{j} y_{j} d j=E$, where $E$ denotes current expenditures. The first-order condition is: $\partial u / \partial y_{j}=1 / y_{j}=\lambda p_{j}$, for all $j$, where $\lambda$ is a Lagrange multiplier. Together with the budget constraint, this implies that $p_{j} y_{j}=1 / \lambda=E$ for all $j$.

${ }^{5}$ See Grossman and Helpman (1991).
} 
it has made in the past, or successfully copied from someone who did: denoting this number as $k_{f} \in \mathbb{N}$,

$$
q_{f}=\gamma^{k_{f}}
$$

where $\gamma>1$ measures the size of a leading-edge environmental innovation. Recalling that consumers value a quantity-quality combination $(y, q)$ as $y q^{\delta}$, it thus effectively takes $c \gamma^{-\delta k_{f}}$ units of labor for a firm at technological level $k_{f}$ to produce one unit of quality-adjusted output.

Suppose from here on that each sector $j$ is constituted of a duopoly, $f=A, B$, plus a "lagging" competitive fringe, as follows. First, in each period $t$ both firms have free access to the frontier technology achieved in period $t-1$. These strong knowledge spillovers considerably simplify the R\&D problem, by limiting to a single period the horizon over which investment costs can be recouped through rents.

Second, a firm's R\&D effort can result in at most one innovation over the current frontier of the sector in which it operates: for any $z \leq 1$, investing $\kappa z^{2} / 2$ units of labor ex ante yields a probability $z$ of inventing a technology that is $\gamma$ times cleaner, and a complementary probability $1-z$ of zero progress. We call $z$ the "innovation rate" or "R\&D intensity" of the firm.

Together, these assumptions imply that the gap that can open between firms is at most one innovation, $\left|k_{B}-k_{A}\right| \in\{0,1\}$, and it resets to zero at the start of every period.

A third assumption made to further simplify the problem is that, at the innovation stage (where $k_{A}=k_{B}$ ), only one (either) of of the two firms has an opportunity to productively invest in R\&D. The other lacks, in the current period, a suitable idea, managerial capacity, access to specialized labor, etc., which effectively makes its $\kappa$ prohibitively large.

To summarize, given our set of assumptions there can, at any point in time, be only be two kinds of sectors in the economy: (i) leveled or neck-and-neck sectors, where the duopolists' qualities are on par, and (ii) unleveled sectors, where a leader is one step ahead of its competitor (laggard or follower).6 More precisely, at the start of each period $t$, which corresponds to the investment phase, all sectors are neck and neck, while during the subsequent production phase of that same period, a fraction $z$ will be unleveled, corresponding (by the law of large numbers) to the R\&D intensity chosen

\footnotetext{
${ }^{6}$ Aghion et al. (2001) and Acemoglu and Akcigit (2012) analyzes the more general innovation model (but without environmental concerns) where there is no limit to how far ahead the leader can get. In such a setting (or, when followers can "leapfrog" ahead) additional effects arise, which we will abstract from for simplicity.
} 
by investing firms.

In addition to the two firms active in each sector, there is also competitive fringe of potential entrants. These firms will neither produce nor do research in equilibrium but act as a threat, disciplining the duopolists. We thus assume that, at the start of each period $t$, the fringe has access, through free imitation, to the "previous-best" (not "previous-period frontier") technology, meaning one that embodies only the $k^{\prime}=k-1$ previous innovations, where $k=k_{A}=k_{B}$ is the level from which the duopolists start, and may further innovate.

\subsection{Competition and profits}

Recall that, due to the preferences in (1), consumers will spend the same amount on each variety. Firms within each sector thus compete for that fixed revenue, normalized to 1.

Consider first market competition in an unleveled sector, where an innovation just occurred. The leader has a quality advantage of $\gamma^{\delta}$ over the follower -its cars pollute $\gamma$ times less- so it can engage in limit pricing: by charging $p_{M}=\gamma^{\delta} c$, it attracts all consumers and captures the whole revenue "pie," which is clearly optimal. The number of units produced and level of operating profits of such a de facto monopolist are then

$$
y_{M}=\frac{1}{p_{M}}=\frac{1}{\gamma^{\delta} c}, \quad \pi_{M}=1-\frac{1}{\gamma^{\delta}}
$$

Consider now competition in a leveled (neck-and-neck) sector, where no innovation recently occurred. If the two firms engage in unfettered (Bertrand) price competition, the equilibrium price falls to $c$, resulting in zero profit for both. At the other extreme, if they collude so effectively as to maximize their joint profits and share the proceeds, they will act like the leader in an unleveled sector. Indeed, the limit price that can be charged is now what will just keep out the competitive fringe, which can produce goods that are $\gamma$ times more polluting than those of the duopolists. The fully collusive strategy will thus again involve $p=c \gamma \delta=p_{M}$, and yield profits of $\pi_{M} / 2$ for each firm. Following Aghion et al. (2005), we span the range between these two extremes by representing (inverse) market competition as the extent to which two neck-and-neck firms are able to collude at the production-and-sales stage. More precisely, we assume 
that the normalized profit of each is:

$$
\pi_{D}(\Delta) \equiv(1-\Delta) \pi_{M}
$$

where $\Delta \in[1 / 2,1]$ parametrizes the degree of product market competition..$^{7}$ The corresponding price and sectoral output are given by equating total profits to total sales minus costs, $2(1-\Delta) \pi_{M} \equiv[p(\Delta)-c] y(\Delta)=1-c / p(\Delta)$, so that

$$
\begin{aligned}
& p(\Delta)=\frac{c}{1-2(1-\Delta) \pi_{M}}=\frac{c}{1-2(1-\Delta)\left(1-\gamma^{-\delta}\right)} \in\left[c, p_{M}\right], \\
& y(\Delta)=\frac{1}{p(\Delta)}=\frac{1}{c}\left[1-2(1-\Delta)\left(1-\gamma^{-\delta}\right)\right] \in\left[y_{M}, \frac{1}{c}\right] .
\end{aligned}
$$

For given technologies, competition (defined here as reduced collusion) has the standard effect of forcing down the equilibrium price, which in turn increases consumer demand and production. More units produced and sold, in turm, result in more emissions -the mass-consumption effect. The other consequence of competition is to affect incentives to innovate, to which we now turn.

\subsection{Clean innovation and the "escape competition" effect}

As explained earlier, each sector starts the current period with both firms being neck and neck, then one of the two (say, at random) is endowed with an opportunity, or idea, for engaging in R\&D. If it invests $z \leq 1$ to try and develop a cleaner technology, it will succeed with probability $z$ and then reap a leader's operating profit $\pi_{M}$; with probability $1-z$ it will fail and have to engage in price collusion with its equally able competitor, reaping only $\pi_{D}$. Investing $z>1$ clearly serves no purpose, so a potential innovator solves

$$
\max _{z \in[0,1]}\left\{z \pi_{M}+(1-z) \pi_{D}(\Delta)-\kappa z^{2} / 2\right\},
$$

resulting in $z=\min \left\{\left(\pi_{M}-\pi_{D}(\Delta)\right) / \kappa, 1\right\}$. We shall restrict attention to parameter values such that $\kappa>\pi_{M}$, or equivalently

$$
\kappa>1-\frac{1}{\gamma^{\delta}} \equiv \kappa_{1}
$$

\footnotetext{
${ }^{7}$ We assume that collusion occurs only at the (ex-post) stage of production and pricing, and not at the ex-ante stage of R\&D, which for instance could be harder to monitor.
} 
meaning that innovations are not too "easy," in terms of their importance or/and cost. The optimal R\&D intensity is then always interior,

$$
z(\Delta)=\frac{\Delta \pi_{M}}{\kappa}=\frac{\Delta}{\kappa}\left(1-\frac{1}{\gamma^{\delta}}\right)
$$

Averaging across all sectors $j \in[0,1]$ the rate of $\mathrm{R} \& \mathrm{D}$ effort at the start of period $t$ is also the proportion of sectors where innovation will occur, so the aggregate flow of clean innovations during the period is simply $I=z(\Delta)$. Therefore:

Proposition 1. Both market competition and consumers' social-responsibility concerns raise investment in, and the total flow of, clean innovations. Moreover, these two forces act as complements:

$$
\frac{\partial I}{\partial \Delta}>0, \frac{\partial I}{\partial \delta}>0, \frac{\partial^{2} I}{\partial \Delta \partial \delta}>0
$$

Remark: One could extend this model by having both: clean and dirty innovation, for example faster or bigger cars (e.g. SUV's), or innovations that save on labor costs. Our conjecture is that in this extended model, more competition, i.e. a higher $\Delta$, would generally enhance both types of innovation, but the proportion of clean would still rise with prosocial values as well as their interaction with market competition.

\subsection{Pollution}

At the production (post-innovation stage) of each period $t$, there is a fraction $z$ of sectors in which one firm has succeeded in becoming cleaner by a factor $\gamma$ than the other, and a fraction $1-z$ where the innovation effort has failed, so that both firms still use period $t-1$ 's frontier technology. Market output is $y_{M}$ in the first case and $y(\Delta)$ in the second, so total emissions (normalized by total expenditure) equal:

$$
X=[1-z(\Delta)] y(\Delta)+z(\Delta) y_{M} / \gamma
$$

Given previous results, this takes the form:

$$
X=\left[1-\frac{\Delta}{\kappa}\left(1-\frac{1}{\gamma^{\delta}}\right)\right]\left(1-2(1-\Delta)\left(1-\frac{1}{\gamma^{\delta}}\right)\right)+\frac{\Delta}{\kappa}\left(1-\frac{1}{\gamma^{\delta}}\right) \frac{1}{\gamma^{\delta+1}} .
$$

This is a concave second-degree polynomial in $\Delta$, intuitively reflecting two opposing effects. On the one hand, by increasing equilibrium output $y(\Delta)$ in neck-and-neck sectors, 
competition directly increases pollution. This is the "China gets cars" effect. On the other hand, the anticipation of lower profits in more competitive markets causes firms to try and gain a monopolistic quality advantage, by increasing their clean-innovation effort; as a result, a greater fraction $z(\Delta)$ of sectors develop clean technologies, which tends to reduce emissions 8

Focusing first on the extremes of full competition and full collusion to get the main intuitions, the former is less polluting than the latter if $X(1)<X(1 / 2)$, which can be simplified to

$$
\kappa<1-\frac{\gamma^{-\delta}}{2}\left(1+\frac{1}{\gamma}\right) \equiv \kappa_{2}
$$

Note that $\kappa_{2}>1-\gamma^{-\delta}=\kappa_{1}$. Quite intuitively, for any given $\kappa$, 11 holds when $\gamma$ or/and $\delta$ is large enough. More generally, we have:

Proposition 2. Assume $\kappa>\kappa_{1}$, so that the optimal $z(\Delta)$ is always interior. As competition $\Delta \in[1 / 2,1]$ increases: (a) for $\kappa<\kappa_{2}-\kappa_{1} / 2$, aggregate pollution $X(\Delta)$ decreases monotonically; (b) for $\kappa>\kappa_{2}+\kappa_{1} / 2, X(\Delta)$ increases monotonically; (c) for $\kappa \in\left(\kappa_{2}-\kappa_{1} / 2, \kappa_{2}+\kappa_{1} / 2\right), X(\Delta)$ is hump-shaped; moreover, it is minimized at $\Delta=1$ (versus $\Delta=1 / 2$ ) if and only if $\kappa<\kappa_{2} ;$ (d) For all $\kappa$ in the nomempty interval $\left[\kappa_{1}, \kappa_{2}\right]$, aggregate pollution is minimized at $\Delta=1$.

The proof is given in the Appendix, as is that for the next proposition, which analyzes the effects of environmental values $\delta$ and their interaction with competition. Both sets of results are illustrated in Figure 1.

Figure 1: Effect of competition and social values on pollution

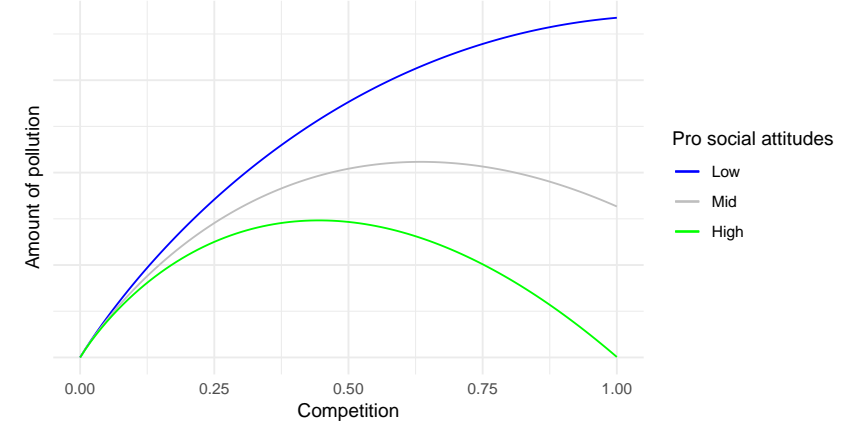

\footnotetext{
${ }^{8}$ Conversely, a higher $\kappa$ reduces $z$ and thereby increases $X$.
} 
Proposition 3. Aggregate pollution $X(\Delta)$ decreases with consumer's social-responsibility concern $\delta$, and for all $\kappa>\kappa_{1}$ (more generally, as long as R\&D effort is interior) it decreases more, the stronger is market competition: $\partial^{2} X / \partial \Delta \partial \delta<0$.

\subsection{Welfare}

Let us start by evaluating aggregate utility from consumption. In each period, there are $z$ relatively "green" varieties and $1-z$ relatively "dirty" ones. Each individual purchases $y_{M}$ of the former and $y(\Delta)$ of the latter, so given their relative valuations by consumers,

$$
U=(1-z(\Delta)) \ln y(\Delta)+z(\Delta) \ln \left[\gamma^{\delta} y_{M}\right]
$$

As expected, an increase in competition $\Delta$ increases aggregate expected utility through both a quantity and a quality effect. First, for fixed $z$ it increases consumption $y(\Delta)$ of each neck-and-neck variety, by driving the price down. Second, it reallocates the composition of the consumption basket towards cleaner varieties (by incentivizing firms to develop them), which consumers prefer: since $y(\Delta)<1 / c=\gamma^{\delta} y_{M}$ for all $\Delta<1$, an increase in $z(\Delta)$ raises $U$.

An increase in prosocial concerns, on the other hand, need not raise utility. On the one hand, a higher $\delta$ means that consumers experience more disutility -e.g., guilt- from each unit of pollution embodied in their consumption. On the other hand, a more environmentally concerned population pushes firms to produce cleaner goods (albeit more expensive ones). The latter effect can be shown, quite intuitively, to dominate when competition is high enough. We show in the Appendix:

Proposition 4. (a) Aggregate utility is increasing in the degree of competition $\Delta$; (b) It increases with the strength of consumers' environmental preferences $\delta$ if and only if competition is strong enough, $\Delta \geq \Delta_{U}$, with $\Delta_{U}<1$ when $\kappa<1+\pi_{M}$ and $\Delta_{U}<1 / 2$ when $\kappa$ is below some $\bar{\kappa}\left(\pi_{M}\right)<\left(1+\pi_{M}\right) ; 2$ (c)If $\kappa \geq 2 \kappa_{1}$, the effects of preferences and competition are complementary, $\partial^{2} U / \partial \Delta \partial \delta>0$.

Consumption utility is only one component of agents' welfare, however: by definition, the total pollution generated by production and/or consumption activities is a harmful externality. Assuming an aggregate disutility linear in total emissions, net social welfare is

$$
W=U-\psi X, \psi>0
$$


These are the only two relevant terms, since: (i) the disutility of labor employed in production and in research is exactly compensated by their wage payments; (ii) these wages, plus firms' profits (net of R\&D costs) are entirely consumed by individuals, so that total income equals total spending on the goods produced. From the above propositions, it follows that:

Proposition 5. (a) For $\kappa \in\left[\kappa_{1}, \kappa_{2}-\kappa_{1} / 2\right]$, net social welfare $W$ increases monotonically with competition; more generally, there is $\widehat{\kappa}>\kappa_{2}$ such that, for all $\kappa \in\left[\kappa_{1}, \hat{\kappa}\right]$, $W$ is maximized at $\Delta=1$; (b) $W$ increases with the strength of consumers' environmental preferences $\delta$ if and only if competition is strong enough, $\Delta \geq \Delta_{W}$, where $\Delta_{W}<\Delta_{U}$; (c) If $\kappa \geq 2 \kappa_{1}$, the effects of preferences and competition are complementary, $\partial^{2} W / \partial \Delta \partial \delta>0$.

\subsection{Predictions}

Proposition 1 states three main predictions we should confront in the data. First, green innovation increases with the degree of consumers' social responsibility. Second, green innovation increases with the extent of competition. Finally, environmental values and market competition are complementary forces in inducing more green innovations.

\section{$3 \quad$ Empirical Strategy}

We now turn to testing empirically the model's key comparative-statics predictions for R\&D. Specifically, we relate the extent to which firms innovate in a clean direction to firm-specific measures of exposure to pro-environmental values and to competition. We thus run regressions of the following form, where $\alpha, \beta$ and $\gamma$ are the main coefficients of interest:

$$
\begin{aligned}
\text { Innovation }_{j, t} & =\alpha \text { Values }_{j, t}+\beta \text { Competition }_{j, t}+\gamma \text { Values }_{j, t} \times \text { Competition }_{j, t} \\
& +\delta X_{j, t}+J_{j}+T_{t}+\varepsilon_{j, t}
\end{aligned}
$$

In our preferred specification, Innovation In $_{,}$is the number of clean patents that firm $j$ filed in period $t$, relative to dirty ones, measured as $\log (1+$ number of clean patents $)$ - $\log \left(1+\right.$ number of dirty patents).9.$^{9}$ We also show results on clean and dirty patents

\footnotetext{
${ }^{9}$ If a firm files the same innovation with with patent offices in several countries we only count one innovation; i.e. effectively we count so called patent families rather than individual patents.
} 
separately. $J_{j}$ are firm fixed effects, and $T_{t}$ period fixed effects for $t=1998-2002$ or 2008-2012. We restrict the analysis to these two periods because of data constraints for pro-environmental attitudes (see below). Standard errors are clustered at the firm level.

Values $_{j, t}$ is a firm-specific measure of exposure to pro-environmental values. It is defined as a weighted average of country-level attitude measures:

$$
\text { Values }_{j, t}=\sum_{c=1}^{41} \omega_{j, c} \times \text { values }_{c, t}
$$

where values $s_{c, t}$ is the prosocial level in country $c$ period $t$ and $\omega_{j, c}$ is our measure of the importance of country $c$ for firm $j$. This approach follows and expands on that of Aghion et al. (2016). In theory one could use the firms' expected sales or profits in each country to infer the weights $\omega_{j, c}$, but such data is not available. We therefore compute it instead using patenting activity from PATSTAT in a pre-period of analysis, based on the principle that protecting intellectual property is more worthwhile where one expects its market to be larger. Aghion et al. (2016) show that this approach yields weights that are very correlated with sales for the firms for which sales data broken down by country are available. More precisely, we define $\omega_{j, c}$ as the share of patents filed in country $c$ by firm $j$, between 1950 and 1995. We restrict attention to the 41 countries for which we have data on both environmental values and competition (for some of the robustness checks using alternative data sources, the set of countries has to be restricted to 25). We show robustness to various alternative definitions of the weights and in particular to recent refinements of this approach by Dechezlepretre et al. (2019)

Our main competition measure for firm $j$ in period $t$ is also similarly defined as a weighted average of country-level indicators. For a subset of firms, we can use a direct firm-level measure of competition that can essentially be interpreted as a Lerner index (see below). Finally, the $X_{j, t}$ are controls, including GDP, population, (tax-inclusive) oil prices and in some specification environmental policies. They are also defined for each firm as a weighted average of country-level variables, with weights computed as above. 


\section{Data sources and summary statistics}

\subsection{Innovation data}

Our innovation measures come from patents in the car industry, as in Aghion et al. (2016). Compared to R \& D investment, patents are available at a very technologically disaggregated level and can thus be classified as clean or dirty. Moreover the auto sector is an innovation-intensive sector, where patents are perceived as an effective means of protection against imitation, something that is not true in all sectors (Cohen et al., 2000). Any given innovation is typically patented in multiple countries. However, the PATSTAT database maintained by the European Patent Office allows us to track all individual patents belonging to the same patent family. A patent family identifies an inventive step that is subsequently patented several times with different patent offices. We use this to count families rather than patents, and refer to a family as an innovation.

To classify innovations as clean or dirty, we rely on the International Patent Classification system (IPC) and on the "Y02 classification system" introduced by the European Patent Office in 2002 to identify innovations that are relevant to mitigate climate impact and which was also applied retrospectively for patents predating its introduction 10 . Clean innovations are those related to non-fossil-fuel-based methods of propulsion, such as electric or hydrogen cars and related technologies (e.g. batteries), while dirty innovations consist of those related to the internal-combustion engine. We define as grey technologies those that improve the efficiency of the internal combustion engine. The exact IPC and Y02 codes used to identify clean, dirty and grey technologies can be found in appendix Table A1. Car-related innovations that do not fit in any of these three categories are labelled as "other". We checked the robustness of our results to various treatments of the "other" and "grey" categories.

Figure 2 shows the worldwide time-series evolution of car-related innovations since the 1960s. The annual number has grown from around 3,000 in the 1960s to over 40,000 in 2010. Up until 2000, this growth is mostly driven by patents in the "other" category, while since 2000 there has also been a very rapid growth of clean patents. Indeed if we focus on the change between 1998-2002 and 2008-2012, the two periods we use for

\footnotetext{
10 https://www.wipo.int/classifications/ipc/en/ and https://www.epo.org/news-issues/ issues/classification/classification.html
} 
Figure 2: Evolution over time of clean, dirty, grey and other car related innovations

(a) Absolute number of innovations

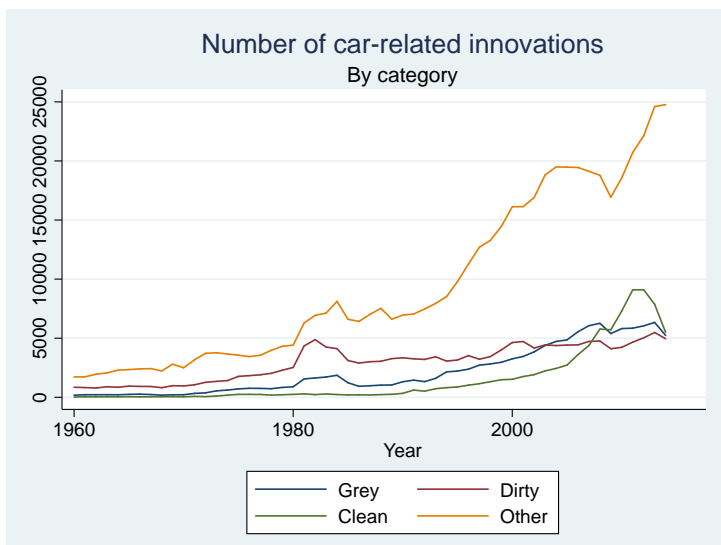

(b) Relative share

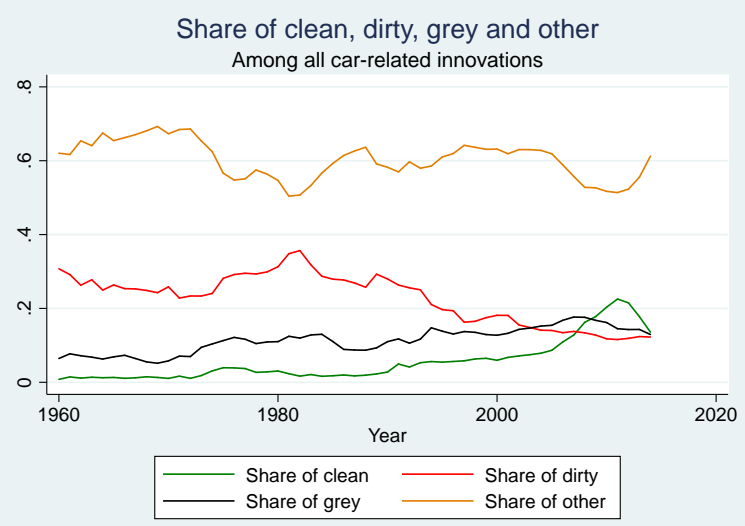

Source: PATSTAT. Patents classified as clean, dirty, grey or other based on the IPC and Y02 classification systems. See main text for more details.

our analysis, the number of dirty innovations has remained roughly constant at around 4,000 per year while the number of clean innovations has increased from 1,600 per year in the first period to 7,400 in the second one. Thus, the share of dirty innovations declined from $20 \%$ in the early 2000 s to just above $10 \%$ towards the end of our sample period, while the share of clean ones rose from $7 \%$ to $20 \%$ (despite a reversal in the last two years of our data).

Our sample consists of all firms in the car industry who patented at least once during either the first period of analysis (1998-2002) or the second one (2008-2012) ${ }^{11}$ This gives us 8,562 firms, out of which 2,130 patented in both periods. In 1998-2002, conditional on patenting, the average number of innovations per firm is 2.3 clean ones and 6.1 dirty ones, while in 2008-2012 these figures are respectively 6 and 3.7. On average, firm level growth rates between the 2 periods is $34 \%$ for clean patents $4 \%$ for dirty patents.

\footnotetext{
${ }^{11}$ The gap in-between is due to the fact that environmental willingness-to-pay questions were asked across countries only during these two periods. We thus take five-year windows centered on 2000 and 2010, and sum up a firm's patents (available annually) over each of them.
} 


\subsection{Environmental values data}

The data on attitudes comes from the International Social Survey Program (ISSP) and the World Value Survey (WVS). Several questions could capture the pro-environment values we are interested in, but they are often asked only in a limited set of countries during a single survey wave. The one question that is common to both surveys and allows us to cover many countries for 2 time periods is the following (as stated in the ISSP): "How willing would you be to pay much higher taxes in order to protect the environment?" Answers vary from 1 ('very willing') to 5 ('very unwilling') and we reverse-code them, so that a higher value means a more pro-environmental attitude. In the WVS, the corresponding question is: "Can you tell me whether you strongly agree, agree, disagree or strongly disagree with the following statement: 'I would agree to an increase in taxes if the extra money were used to prevent environmental pollution." Answers are 1 ('strongly agree'), 2 ('agree'), 4 ('disagree') and 5 ('strongly disagree'). We code as 3 the 'don't know' answers and reverse-code the others, as for the ISSP, so that a higher value means a more pro-environmental attitude.

Because taxes pertain to public policy more directly than to consumer spending decisions, we also use one additional variable from each survey to create a pro-environment index. For ISSP, the question is: "How willing would you be to pay much higher prices in order to protect the environment?". For the WVS, it is about (dis)agreement with the statement: "I would give part of my income if I were certain that the money would be used to prevent environmental pollution". Answers are again reverse coded to ensure consistency. We then average all variables at the country-period level, transform them into z-scores, and eventually average across all variables available for the countryperiod observation. We thus have data on willingness-to-pay for the environment for 41 countries for 2 periods, namely 2000 and 201012 .

In most countries, pro-environmental values have decreased over this period. This is not a specificity of the datasets we are using, nor of the exact point in time at which our attitude variables were measured. Indeed, Figure 3 provides a time-series plot of average answers to another environmental preferences question, asked by the Gallup survey to US respondents. We see that the prevailing trend from the early 1990s to the

\footnotetext{
${ }^{12}$ Note that this covers most major economies, and in particular most countries in which firms innovating in the automotive sector reside, although there are a few notable exceptions such as Italy and Spain.
} 
beginning of the 2010 decade has been a sharp reduction in environmental concerns. The reasons for this decline are unclear, and there is even little awareness yet of this fact in the literature. Gallup conjectures that environmental preferences increase when the unemployment rate decreases and vice versa, but although this explanation may hold for the US it does not fit well for other countries. Figure 3 also shows a sharp reversal after our period of analysis. Although we do not have such recent data for other countries, we hypothesize that this might be a more general trend. Therefore in the last section of the paper, we will forecast what our estimates would imply in terms of green innovations if the decrease in environmental values during the first decade of the 2000s was totally erased by the more recent uptake in environmental concerns

Figure 3: Long run decline and recent reversal in pro-environmental concerns

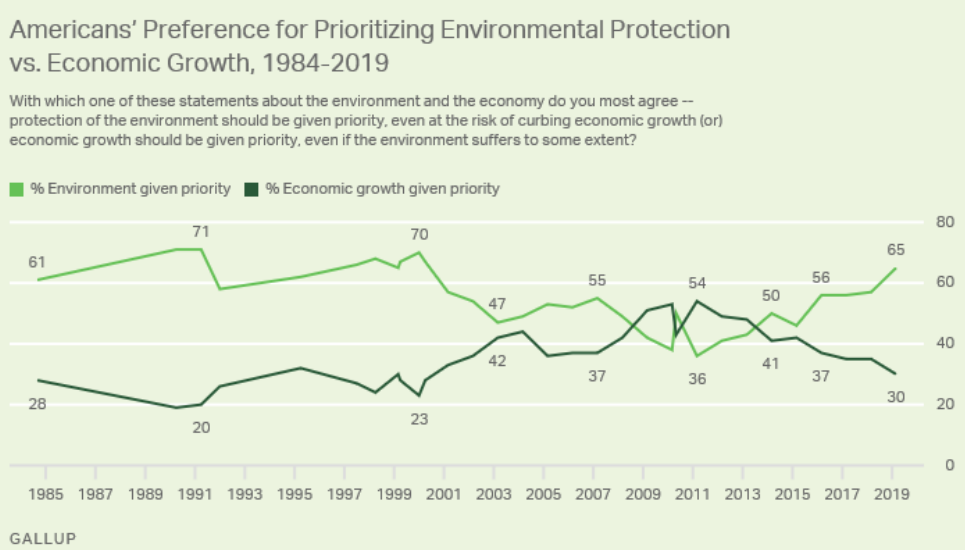

Source: "Preference for Environment Over Economy Largest Since 2000", by Lydia Saad for Gallup News, April 2019

In our data, the countries that experienced the strongest decrease in our pro-environmental index between 2000 and 2010 are the Netherlands, Poland, Ireland, Croatia and the Czech Republic, while France, Germany, Korea, Moldovia and Lituania had the biggest increase. In terms of levels, the 5 countries with the highest score in 2000 were Switzerland, the Netherlands, Denmark, Israel and Greece, while ten years later it was Korea, Denmark, Switzerland, Greece and Moldovia. The lowest ones were Lituania, France, Hungary, Estonia and Germany in 2000 and Lituania, Latvia, Poland, Ireland and Argentina in 2010. 


\subsection{Competition data}

To measure competition, we use two approaches. The first one relies on country-level measures, which we aggregate at the firm level using the same weights as for the environmental values; the second one is a direct firm-level measure of competition, but it is available only for a subset of firms.

Our main country-level competition indicator is the World Bank's oppenness measure, defined as imports + exports divided by GDP. The most open countries in both periods are Ireland, Luxembourg and some Eastern European nations, while the least open are Japan, the US, Argentina and Turkey. In terms of change between the 2 periods, Luxembourg and Eastern Europe saw the biggest increases in openness, while the largest decreases were observed in Canada, Norway, Russia and New Zealand. We also use, for robustness checks, the Product Market Regulation (PMR) indicator from the OECD (Koske and Barbiero, 2015). It is a comprehensive variable that aggregates responses from a questionnaire of over 700 questions, falling into three main areas: state control, barriers to entrepreneurship, and barriers to trade and investment. We use it for robustness and not as our benchmark measure, because it does not cover as many countries and years as the World Bank measure. The openness measure and the OECD competition measure correlate with a coefficient of 0.3 . Indeed some countries rank very differently along the two measures, like the US which are among the least open according to the World Bank but the most competitive besides Great Britain according to the OECD.

Of course, these country-level measures of openness or regulation are only imperfect proxies for the actual levels of competition that firms in the auto sector are facing. To compute a more direct firm-level measure, we rely on a Lerner-Index-style approach, which we derive from a structural production-function regression. Compared to a standard Lerner Index, this allows for non-constant returns to scale, as well as quasifixed production factors. A detailed description of the methodology can be found in Appendix B. This approach requires using balance-sheet data from another dataset (ORBIS), and the merge between ORBIS data and our main patent data is only possible for a subset of firms.

The firm-level measure that focuses more specifically on the automobile sector displays 
much less heterogeneity in trends than the country-level indicators. Panel (a) of Figure 4 shows deciles of the distribution of markups over marginal costs - i.e., the inverse of the Lerner Index - across firms. It indicates that markups (and thus competition) have been flatlining over time, with the exception of the top decile, where we see an upward trend from 2003 onwards. Panel (b) shows changes in market power for continuing firms between 2002 and 2012. Thus, for the majority of automobile firms, the general picture is that of a reduction in market power during that time period ${ }^{13}$.

Figure 4: Firm-level Markups

(a) Distribution over time

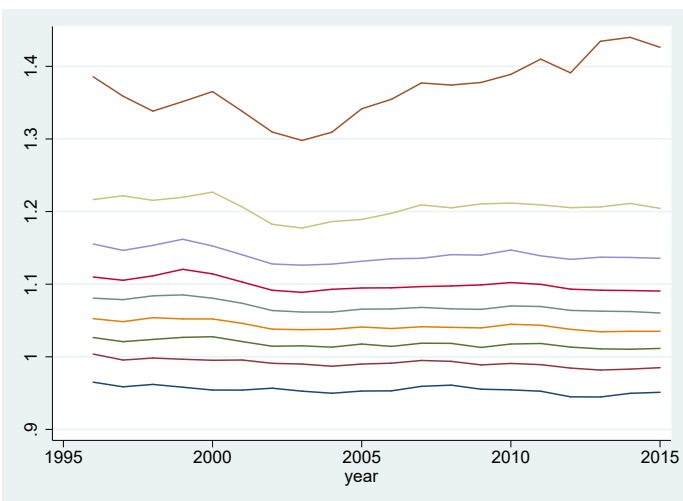

(b) Change between the 2 periods

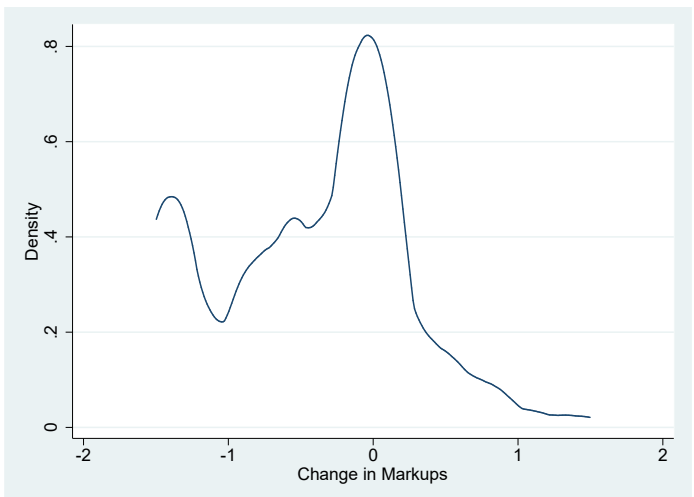

Notes: Panel (a) shows centiles (10th to 90th percentile) of firm-level markups (inverse of the Lerner index) over time. Panel (b) show the distribution of changes in markups between 2002 and 2012. These markups are computed using ORBIS data.

\subsection{Country-level controls}

We use several other country-level annual data sources to get control variables: enduser, tax-inclusive automotive fuel prices from the International Energy Agency (IEA), GDP from the World Bank (in constant 2010 US dollars), and population from the IMF World Economic Outlook database. In some specifications we also control for environmental policies with the Environmental Policy Stringency (EPS) Index from the OECD, which provides a comprehensive measure of the extent of environment-related

\footnotetext{
${ }^{13}$ These observations are interesting in light of recent discussions about so called superstar firms (e.g. Autor \& al., 2017). While panel (a) would seem broadly supportive of the idea that some firms at the top of the distribution were able to gain increasing amounts of market power, panel (b) suggests that this could be the result of compositional changes, that is, firms with low market power exiting along with weaking market power in remaining firms.
} 
regulations, taxes, tarifs and $R \& D$ subsidies ${ }^{14}$. All these country-level indicators are transformed into firm-level variables through the same weighting approach as for the main regressors

\subsection{Patent portfolio weights}

Most of the variables used in the analysis are constructed using the weights we assign to each country, for each firm. Thus it is quite critical to show robustness to various definitions. Our benchmark definition is the share of patents deposited in the various countries over the period 1950-1990. We do not restrict attention to only clean or dirty patents, nor to patents related to automobile, rather we include all patents of the firm in the countries used for the analysis. In the robustness checks, we show results when we include only car-related patents, or when we include only patents with at least one citation, which are supposed to be more meaningful patents.

However, based on the idea that large countries probably matter a lot even for firms that did not patent there in the pre-period, we also use an alternative definition, which incorporates pre-period GDP 15 . The weights then become:

$$
\omega_{j, c}=\frac{\omega_{j, c} \times G D P_{c, p r e-p e r i o d}}{\sum_{c=1}^{41} \omega_{j, c} \times G D P_{c, \text { pre-period }}} .
$$

Following Dechezlepretre et al. (2019), we also show results where we use GDP to the power 0.35 . The idea is that larger markets attract more firms so that the market size per firm will generally not grow 1 for 1 with country size 16

More than half of firms in our sample did not patent in the pre-period in the relevant set of countries. We assign them uniform weights for each country, but also show results when we drop them or assign them for each country the average weight among firms that did patent in the pre-period. We implement the uniform weights by adding 1 to the number of patents a firm in a given country. This ensures a smooth transition

\footnotetext{
${ }^{14}$ For more details see https://stats.oecd.org/Index.aspx?DataSetCode=EPS

${ }^{15}$ We also checked robustness with using GDP per capita instead of GDP, but it seems that market size is what matters most

${ }^{16}$ Eaton, Kortum and Kramarz (2011) estimate the elasticity of French exports to GDP of the destination country to be 1 and the elasticity of the number of French exporters to be 0.65 . This gives an elasticity of the average export by firm of 0.35
} 
between firms with and without pre-sample patents. ${ }^{17}$ However, we check robustness with and without this transformation.

Whatever the definition, the US has the largest weight, on average between 7 and $16 \%$ depending on the definition, followed by Germany, Japan, the UK and then France. When we incorporate GDP, the weights of the small countries, for instance from Eastern Europe, become negligible.

\section{Empirical results}

\subsection{Main results}

Table1 reports our benchmark results from specification (13). Panel A shows the main effects of pro-environmental values and of competition on the direction of innovation in the car industry. Panel B adds an interaction term between values and competition. The difference between each column is in the dependent variable. While column (1) shows our main outcome of interest, namely the growth rate of clean innovation relative to dirty, column (2) and (3) report the effects on clean and dirty innovation separately. Finally, columns (4) and (5) respectively use as outcomes grey innovation and all the "other" car-related innovation not classified as either clean, dirty or grey.

We see that "greener" consumer values push innovation in the clean direction, by reducing the rate of growth of dirty innovations. Competition has a strong significant positive effect on clean innovation, but it actually increases all types of innovation. Thus, although the effect is stronger on clean than dirty, the difference is not statistically significant. Panel B shows that the interaction between values and competition has a significant positive effect on the growth rate of clean innovations, both in absolute (column 2) and relative to dirty innovations (column 1).

To facilitate the interpretation of magnitudes, all variables are z-scores. Using estimates from column 1's panel B, we see that a one-standard-deviation increase in exposure to pro-environmental values is associated with a growth rate of clean patents $14 \%$ higher than that of dirty patents, at the mean level of competition. This effect increases to $17 \%$ for levels of competition one standard deviation higher than the mean.

\footnotetext{
${ }^{17}$ Suppose a firm holds only patent in one country A (in the pre-period). In our main specification this firm would be assigned weights that are very similar to a firm without patents. In the alternative specification, the weight for country A would be equal to 1 whereas all other weights are equal to 0 .
} 
As expected from Aghion et al. (2016), an increase in fuel prices is also associated with a higher growth rate of clean patents relative to dirty ones.

The model outlined above had three comparative statics, out of which only two find strong support in the data. Pro-environmental values push innovation in the clean direction, all the more so that competition is high. The effect of competition on its own is however a bit more ambiguous since it fosters innovations in general, with a small but insignificant advantage towards cleaner innovations.

\subsection{Robustness checks}

Table 2 shows robustness to various weights definitions. Column 1 is the same as column 1 of panel B in Table 1, which is our benchmark. In column 2, we incorporate countries' GDPs in the weight definition, to account for the fact that larger markets matter more (see section 4.5). Column 3 is the same as column 2, except that GDP is raised to the power 0.35. In Column 4 we do not add one to the patent stocks of firms in each country. In column 5, we drop firms with no pre-period patenting activity (who are otherwise assigned uniform weights). In column 6 we assign these firms the average weight obtained for firms who did patent in the pre-period. Column 7 and 8 restrict the set of patents from the pre-period used to compute the weights: in column 7 only car-related patents are considered, while in column 8 only patents with at least one citation are included. Results are very consistent across specifications, with a significant positive effect on clean innovation of values and of the interaction between values and competition. The magnitudes are quite similar, although column 4 yields a smaller coefficient for the main effect of values, while columns 6 through 8 yield a larger one.

Table 3 shows that our results are robust to controlling for environmental policies. This table reproduces panel B of Table 1, with the Environmental Policy Stringency Index of the OECD as additional control. This new variable is only available for 25 countries, hence we have to recompute the weights within this smaller set of countries. As was already the case in Aghion et al. (2016), environmental policies do not appear to be a significant determinant of innovations: the coefficient of the EPS index on the growth rate of clean innovations relative to that of dirty ones is insignificant. More importantly, we see that this new control hardly affects the positive significant coef- 
ficient of values and that of the interaction between competition and values. But it makes the competition effects on all types of innovations besides the grey ones become insignificant.

Table 4 shows robustness to alternative measures of competition or values. Column 1 is the benchmark, identical to column 1 of Table 2 . In column 2 we use the "higher tax" question only, instead of our index, to proxy for the willingness-to-pay for the environment. In column 3 we use the firm-level Lerner type measure of competition, while in column 4 we use the OECD Product Market Regulation measure. The positive effect of values on clean innovations relative to dirty ones remains very robust to all these changes, despite the control for environmental policies. The effect of competition is insignificant across columns and that of the interaction term between values and competition is positive and significant, or marginally so, except in the last specification.

Table 5 shows robustness to alternative treatment of the "grey" and "other" categories. Grey refers to patents which make the ICE cleaner, which is neither perfectly clean nor totally dirty. "Other" are innovations that arguably can be classified as "dirty". In our benchmark specifications we drop the grey and other patents but in this table we show results when they are included. In column (1), grey is included in the dirty category, in column (2) it is included in the clean category and in column (3) dirty consists of dirty, grey and other patents. We see that these changes do not affect results much except when grey is classified as clean, we find a strong significant coefficient for the main effect of competition.

\section{Accouting and counterfactual exercises}

Our results show that more prosocial attitudes, especially when leveraged by increased competition, tilt the direction of technology towards the development of cleaner products. While these results are significant, the question remains how economically relevant the effects are.

First, we consider the changes between our two sampling periods, i.e. 1997-2002 (Period 1) vs 2007-2012 (Period 2). As we can see from Table 6, the share of clean innovations increased by nearly 24 percentage points (from 18 to 42 percent) while 
the share of dirty innovations decreased by over 20 percentage points. How can this be reconciled with the fact that citizens in our sample countries generally became less concerned with environmental priorities between 2000 and 2010 (see Table 7)? The answer to the puzzle is two-fold. First, and predictably, during that period there was a sharp rise in (tax-inclusive) fuel prices, which on its own induces some substitution towards cleaner automotive products. Second, and more interestingly, the trend in environmental concerns was quite different across countries, and in fact a favorable one in those countries that mattered the most for innovation during that period. As a result of this key compositional effect, which also demonstrates the importance of a disaggregated analysis, the relevant changes in environmental attitudes between 1998 and 2012 actually made an important positive contribution to making the overall mix of patents cleaner, both on their own and when amplified by changes in competition, even though the unweighted index of those attitudes declined.

Using our fitted model, we examine what would have happened if the only thing that changed between periods 1 and 2 were the observed changes in social attitudes. We find that the clean innovation share would have increased by 5.7 percentage points, whereas the dirty innovation share would have decreased by 4.6 p.p. (see column 2 of Table 6), despite an average decline in the unweighted pro-environmental attitude index. Analogously, Column 3 of Table 6 considers what would have happened if the only change between period 1 and 2 was the observed changes in competition. Again we see an increase of the clean innovation share (by 7 percentage points) and a reduction of the dirty innovation share (by 7.3 p.p.). Moreover, in column 4 we observe that the combined effect of the change in attitudes, the change in competition and their interaction increases the clean innovation share by 7.4 percentage points. In other words: the combined effect of the change in attitudes and the change in competition accounts for more than one third of the observed changes in the clean innovation share. Column 5, finally, considers the combined impact of social attitude, competition and price changes. This amounts to an increase of the clean share by 29 pcps; i.e. more than the actual changes. We can consequently infer that other factors (possibly, the Great Recession) must have had a dampening effect on the shift towards clean.

In Table 8, we consider a different, prospective, scenario. We examine what would happen if - given the period 2 values - we observed a further increase in both competition and prosocial attitudes. To simulate the effect of realistic changes, we take 
the average absolute change seen between period 1 and 2 (see Table 7), that is, 0.74 standard deviations for prosocial values and 0.91 standard deviations for competition. For prosocial values, the historical change between the two periods was a decrease and we will now simulate the effect of a reversal of this decrease, whereas for competition the historical change was already an increase and we will consider a further increase of the same magnitude. We find that a uniform 0.74 standard deviation increase in prosocial attitudes alone increases the clean share by 1.8 percentage points (compared to period two values). A 0.91 standard deviation increase in competition alone raises it by 2 percentage points. The combined effect of both changes is a 4.3 percentage point increase in the clean share.

It is instructive to compare these changes with the equivalent (uniform) change in fuel prices that would induce the same overall effect (see row 2 of Table 8). The simultaneous changes in attitudes and competition just described is equivalent to an increase of $40 \%$ in fuel prices world wide. Given the often dramatic public responses against even moderate attempts to increase fuel prices (e.g. "Gilet Jaunes") this suggests that grassroots and public campaigns to promote citizens' environmental responsibility could be a viable alternative policy option, especially when combined with more competitive markets. 


\section{Conclusion}

Are citizens' oft-stated desires to adopt more environmentally responsible behaviors just "cheap talk", or conversely powerful motivations that end up having a major influence on what new products will be developed and sold? And what is the potential role of market competition in the process? To answer these questions, we brought together patent data, survey data on environmental values, and competition data, to analyze the joint effect of consumers' social responsibility and product-market competition on automotive firms' decision whether to innovate clean or dirty. We found supporting evidence for the idea that pro-environment attitudes and its interaction with competition both have a significantly positive effect on the probability for a firm to aim at cleaner patents. Our results are robust to a broad set of indicators for environmental values and product market competition.

More generally, the results provide support for models in which intrinsically and reputationally motivated individuals incur costs to act in a "socially responsible" manner" in spite of having a negligible impact on the aggregate outcome, such as pollution. When further leveraged by strong competition between firms, moreover, such prosocial motivations can actually "move markets", even at the upstream stage of product research and development.

Although the empirical part of our analysis remains more positive than normative, its findings also suggest that a conjunction of educational policies aimed at increasing consumers' environmental awareness, together with a more active competition policy, can be quite effective, all the more so when direct instruments such as fuel or carbon taxes face strong popular opposition. In particular, our empirical analysis suggests that the combination of historically realistic increases in both prosocial attitudes and product market competition (respectively 1 and 0.75 standard deviations) would have the same effect on green innovation as a $40 \%$ increase in fuel prices worldwide. Further amplifying effects are likely in the long run, as formal laws simultaneously respond to, and in return shape, the evoluation of societal values and norms (Bénabou and Tirole 2011; Ali and Bénabou 2020)

This paper should be seen as a first step in a broader research agenda. First, it would be interesting to extend the empirical analysis beyond the car manufacturing industry for instance to the energy sector. Second, one could investigate the effect of shareholders' and other investors' social responsibility on green innovation. These and other extensions are left for future research. 


\section{References}

Acemoglu, D., Aghion, P., Bursztyn, L., and D. Hemous (2012), "The Environment and Directed Technical Change", American Economic Review 102(1): 131-66.

Acemoglu, D., Akcigit, U., Hanley, D, and W. Kerr (2016), "Transition to Clean Technology", Journal of Political Economy 124(1): 52-104.

Aghion, P., Bloom, N., Blundell, R., Griffith, R. and P. Howitt (2005), "Competition and Innovation: An Inverted-U Relationship", Quarterly Journal of Economics, $120,701-728$.

Aghion, P., Harris, C., Howitt, P., and J. Vickers (2001) "Competition, Imitation and Growth with Step-by-Step Innovation" Philippe Aghion, Christopher Harris, Peter Howitt and John Vickers The Review of Economic Studies, Vol. 68, No. 3, pp. $467-492$

Aghion, P., A. Dechezlepretre, D. Hemous, R. Martin, And J. Van Reenen (2016) "Carbon Taxes, Path Dependency, and Directed Technical Change: Evidence from the Auto Industry," Journal of Political Economy, 124, 1-51.

Ali, S and R. Bénabou (2020), "Image Versus Information: Changing Societal Norms and Optimal Privacy", American Economic Journal: Microeconomics, forthcoming.

Autor, D., Dorn, D., Katz, L., Patterson, C., and J. Van Reenen (2017), "The Fall of the Labor Share and the Rise of Superstar Firms", NBER Working Paper No. 23396.

Bartling, B., Weber, R., and L. Yao (2015) "Do Markets Erode Social Responsibility?", The Quarterly Journal of Economics, 130(1): 219266,

Bénabou, R. and J. Tirole (2010) "Individual and Corporate Social Responsibility," Economica, 77 , 1-19.

Bénabou, R. and J. Tirole (2010) "Laws and Norms", NBER Working Paper 7579, November.

Cohen, W., Nelson, R., and J. Walsh. (2000), Protecting Their Intellectual Assets: Appropriability Conditions and Why U.S. Manufacturing Firms Patent or Not. Working Paper no. 7552, NBER, Cambridge, MA. 
Dechezlepretre, A., Hemous, D., Olsen, M. and C. Zanell (2019) "Automating Labor: Evidence from Firm-level Patent Data", Working Paper

Djankov, S., La Porta, R. Lopez-de-Silanes, F. and A. Shleifer (2002), "The Regulation of Entry" , The Quarterly Journal of Economics, 117: 1-37.

Falk, A. and N. Szech (2013), "Morals and Markets" Science, 340(6133): 707-711

Friedman, M. (1970), "The Social Responsibility of Business is to Increase Its Profits," New York Times Magazine, September 13

Franzen, A. and D. Vogl (2013), "Two decades of measuring environmental attitudes: A comparative analysis of 33 countries " Global Environmental Change, Volume 25, No 5, 1001-1008.

Hart, O. and L. Zingales (2019), "Companies Should Maximize Shareholder Welfare Not Market Value", forthcoming in the Journal of Law, Finance, and Accounting.

Koske, I. and O. Barbiero (2015): "The 2013 Update of the OECD Product Market Regulation Indicators: Policy Insights for OECD and Non-OECD countries," Tech. rep., OECD.

Newell, R., Jaffe, A., and R. Stavins (1999) "The Induced Innovation Hypothesis and Energy-Saving Innovation", Quarterly Journal of Economics, 114 (3): 941-975.

Nordhaus, W. (1994), Managing the Global Commons: The Economics of Climate Change. Cambridge, MA: MIT Press.

Nordhaus, W. (2002), "Modeling Induced Innovation in Climate-Change Policy." In Technological Change and the Environment, edited by A. Grübler, N. Nakicenovic and W. D. Nordhaus, 182- 209. Washington, D.C.: Resources for the Future Press.

Popp, D. (2002), "Induced Innovation and Energy Prices", American Economic Review, 92 (1): 160-180.

Stern, N (2007), The Economics of Climate Change: The Stern Review. New York: Cambridge University Press. 
Vives, X. (2008), "Innovation and Competitive Pressure", The Journal of Industrial Economics, 56(3): 419-469.

Weitzman, M. (2007), "A Review of the Stern Review on the Economics of Climate Change" , Journal of Economic Literature 45(3): 703-24.

Weitzman, M. (2009), "On Modeling and Interpreting the Economics of Catastrophic Climate Change", Review of Economics and Statistics 91(1): 1-19. 


\section{Tables}

Table 1: The effect of Values and Competition on the direction of innovation

\begin{tabular}{|c|c|c|c|c|c|}
\hline VARIABLES & $\begin{array}{c}(1) \\
\log (1+\# \text { clean }) \\
-\log (1+\# \text { dirty })\end{array}$ & $\begin{array}{c}(2) \\
\log (1+\# \text { clean })\end{array}$ & $\begin{array}{c}(3) \\
\log (1+\# \text { dirty })\end{array}$ & $\begin{array}{c}(4) \\
\log (1+\# \text { grey })\end{array}$ & $\begin{array}{c}(5) \\
\log (1+\# \text { other })\end{array}$ \\
\hline & \multicolumn{5}{|c|}{ Panel A: Values and Competition main effects } \\
\hline \multirow[t]{2}{*}{ Values } & $0.107^{* * *}$ & 0.00473 & $-0.103^{* * *}$ & -0.0191 & $-0.136^{* * *}$ \\
\hline & $(0.0211)$ & $(0.0191)$ & $(0.0179)$ & $(0.0157)$ & $(0.0239)$ \\
\hline \multirow[t]{2}{*}{ Competition } & 0.269 & $0.514^{* * *}$ & $0.246^{*}$ & $0.381^{* * *}$ & $0.555^{* * *}$ \\
\hline & $(0.166)$ & $(0.144)$ & $(0.128)$ & $(0.108)$ & $(0.162)$ \\
\hline \multirow[t]{2}{*}{ Log fuel price } & $0.965^{* * *}$ & $0.784^{* * *}$ & -0.181 & -0.0386 & $0.603^{* * *}$ \\
\hline & $(0.156)$ & $(0.138)$ & $(0.127)$ & $(0.114)$ & $(0.161)$ \\
\hline Observations & 17,124 & 17,124 & 17,124 & 17,124 & 17,124 \\
\hline R-squared & 0.122 & 0.179 & 0.026 & 0.052 & 0.050 \\
\hline \multirow[t]{2}{*}{ Number of firms } & 8,562 & 8,562 & 8,562 & 8,562 & 8,562 \\
\hline & \multicolumn{5}{|c|}{ Panel B: Adding interaction term between Values and Competition } \\
\hline \multirow[t]{2}{*}{ Values } & $0.141^{* * *}$ & 0.0350 & $-0.106^{* * *}$ & -0.0276 & $-0.0859 * * *$ \\
\hline & $(0.0270)$ & $(0.0230)$ & $(0.0225)$ & $(0.0200)$ & $(0.0289)$ \\
\hline \multirow[t]{2}{*}{ Competition } & 0.167 & $0.422^{* * *}$ & $0.255^{* *}$ & $0.406^{* * *}$ & $0.403^{* *}$ \\
\hline & $(0.165)$ & $(0.140)$ & $(0.126)$ & $(0.107)$ & $(0.161)$ \\
\hline \multirow[t]{2}{*}{ ValuesXComp } & $0.0296^{* *}$ & $0.0268^{* *}$ & -0.00278 & -0.00750 & $0.0441 * * *$ \\
\hline & $(0.0136)$ & $(0.0116)$ & $(0.0110)$ & $(0.00994)$ & $(0.0139)$ \\
\hline \multirow[t]{2}{*}{ Log fuel price } & $0.596^{* * *}$ & $0.450^{* * *}$ & -0.146 & 0.0549 & 0.0527 \\
\hline & $(0.171)$ & $(0.149)$ & $(0.154)$ & $(0.140)$ & $(0.215)$ \\
\hline Observations & 17,124 & 17,124 & 17,124 & 17,124 & 17,124 \\
\hline R-squared & 0.123 & 0.180 & 0.026 & 0.052 & 0.053 \\
\hline Number of firms & 8,562 & 8,562 & 8,562 & 8,562 & 8,562 \\
\hline
\end{tabular}

Note: Besides the coefficients shown, all specifications control for log of population and log of GDP and include firm fixed effects and a period fixed effect. Values, Competition and log of fuel prices are standardized as z-scores. 
Table 2: Robustness to different weights definition

\begin{tabular}{lccccccccc}
\hline & $(1)$ & $(2)$ & $(3)$ & $(4)$ & $(5)$ & $(6)$ & $(7)$ & $(8)$ \\
VARIABLES & \multicolumn{7}{c}{$\log (1+$ \#clean $)$} & $-\log (1+$ \#dirty $)$ \\
Values & $0.141^{* * *}$ & $0.139^{* * *}$ & $0.121^{* * *}$ & $0.0418^{* *}$ & $0.168^{* * *}$ & $0.503^{* * *}$ & $0.546^{* * *}$ & $0.286^{* * *}$ \\
& $(0.0270)$ & $(0.0263)$ & $(0.0304)$ & $(0.0177)$ & $(0.0314)$ & $(0.0998)$ & $(0.180)$ & $(0.0737)$ \\
Competition & 0.167 & 0.118 & 0.0103 & 0.0747 & 0.173 & $0.323^{*}$ & 0.115 & 0.460 \\
& $(0.165)$ & $(0.182)$ & $(0.218)$ & $(0.0703)$ & $(0.181)$ & $(0.165)$ & $(0.485)$ & $(0.284)$ \\
ValuesXComp. & $0.0296^{* *}$ & $0.0319^{* *}$ & $0.0303^{*}$ & $0.0525^{* * *}$ & $0.0430^{* *}$ & $0.150^{* * *}$ & $0.113^{* *}$ & $0.0903^{* * *}$ \\
& $(0.0136)$ & $(0.0143)$ & $(0.0170)$ & $(0.0130)$ & $(0.0191)$ & $(0.0396)$ & $(0.0478)$ & $(0.0329)$ \\
Log fuel price & $0.596^{* * *}$ & $0.559^{* * *}$ & $0.519^{* * *}$ & 0.0998 & $0.643^{* * *}$ & -0.492 & 0.613 & $0.552^{* *}$ \\
& $(0.171)$ & $(0.160)$ & $(0.152)$ & $(0.0647)$ & $(0.186)$ & $(0.901)$ & $(0.467)$ & $(0.278)$ \\
Observations & & & & & & & & \\
R-squared & 17,124 & 17,124 & 17,124 & 17,124 & 6,704 & 17,124 & 17,124 & 17,124 \\
Number of firms & 0.123 & 0.122 & 0.121 & 0.102 & 0.176 & 0.121 & 0.121 & 0.120 \\
\hline
\end{tabular}


Table 3: Robustness to controlling for environmental policies

\begin{tabular}{|c|c|c|c|c|c|}
\hline VARIABLES & $\begin{array}{c}(1) \\
\log (1+\# \text { clean }) \\
-\log (1+\# \text { dirty }) \\
\end{array}$ & $\begin{array}{c}(2) \\
\log (1+\# \text { clean })\end{array}$ & $\begin{array}{c}(3) \\
\log (1+\# \text { dirty })\end{array}$ & $\begin{array}{c}(4) \\
\log (1+\# \text { grey })\end{array}$ & $\begin{array}{c}(5) \\
\log (1+\text { \#other })\end{array}$ \\
\hline Values & $\begin{array}{c}0.109^{* * *} \\
(0.0242)\end{array}$ & $\begin{array}{l}0.00174 \\
(0.0197)\end{array}$ & $\begin{array}{c}-0.107^{* * *} \\
(0.0213)\end{array}$ & $\begin{array}{c}-0.0474^{* * *} \\
(0.0181)\end{array}$ & $\begin{array}{c}-0.112^{* * *} \\
(0.0294)\end{array}$ \\
\hline Competition & $\begin{array}{c}-0.0123 \\
(0.215)\end{array}$ & $\begin{array}{c}0.265 \\
(0.174)\end{array}$ & $\begin{array}{c}0.277 \\
(0.201)\end{array}$ & $\begin{array}{c}0.435^{* * *} \\
(0.161)\end{array}$ & $\begin{array}{c}0.378 \\
(0.264)\end{array}$ \\
\hline ValuesXComp & $\begin{array}{c}0.0224^{* *} \\
(0.0106)\end{array}$ & $\begin{array}{l}0.0231^{* *} \\
(0.00924)\end{array}$ & $\begin{array}{l}0.000670 \\
(0.00879)\end{array}$ & $\begin{array}{l}-0.00718 \\
(0.00793)\end{array}$ & $\begin{array}{c}0.0376^{* * * *} \\
(0.0116)\end{array}$ \\
\hline Log fuel price & $\begin{array}{c}0.559^{* * *} \\
(0.167)\end{array}$ & $\begin{array}{l}0.245^{*} \\
(0.144)\end{array}$ & $\begin{array}{c}-0.314^{* *} \\
(0.148)\end{array}$ & $\begin{array}{l}-0.0648 \\
(0.130)\end{array}$ & $\begin{array}{l}-0.234 \\
(0.210)\end{array}$ \\
\hline EPS & $\begin{array}{c}0.235 \\
(0.146)\end{array}$ & $\begin{array}{c}0.161 \\
(0.120)\end{array}$ & $\begin{array}{c}-0.0743 \\
(0.138)\end{array}$ & $\begin{array}{l}0.0615 \\
(0.111)\end{array}$ & $\begin{array}{l}-0.237 \\
(0.198)\end{array}$ \\
\hline Observations & 17,124 & 17,124 & 17,124 & 17,124 & 17,124 \\
\hline R-squared & 0.121 & 0.180 & 0.025 & 0.052 & 0.050 \\
\hline Number of firms & 8,562 & 8,562 & 8,562 & 8,562 & 8,562 \\
\hline
\end{tabular}


Table 4: Robustness to alternative value and competition measures

\begin{tabular}{lcccc}
\hline \multirow{2}{*}{ VARIABLES } & $(1)$ & $(2)$ & $(3)$ & $(4)$ \\
\hline \multirow{2}{*}{ Values } & \multicolumn{2}{c}{$\log (1+$ \#clean $)-\log (1+\#$ dirty $)$} \\
Competition & $0.109^{* * *}$ & $0.153^{* * *}$ & $0.177^{* * *}$ & $0.102^{* * *}$ \\
& $(0.0242)$ & $(0.0500)$ & $(0.0421)$ & $(0.0250)$ \\
ValuesXCompetition & -0.0123 & 0.283 & 0.00387 & 0.00949 \\
& $(0.215)$ & $(0.223)$ & $(0.0319)$ & $(0.124)$ \\
Log fuel price & $0.0224^{* *}$ & $0.0546^{* *}$ & $0.0658^{*}$ & 0.0162 \\
& $(0.0106)$ & $(0.0217)$ & $(0.0352)$ & $(0.0161)$ \\
EPS & $0.559^{* * *}$ & 0.402 & $1.416^{*}$ & $0.722^{* * *}$ \\
& $(0.167)$ & $(0.269)$ & $(0.731)$ & $(0.258)$ \\
Competition measure & 0.235 & $0.398^{* * *}$ & 0.124 & $0.328^{* *}$ \\
Values measure & $(0.146)$ & $(0.150)$ & $(0.256)$ & $(0.148)$ \\
Observations & & & & \\
R-squared & Index & Higher Tax & Index & Index \\
Number of firms & 17,124 & 17,124 & 2,706 & 17,124 \\
\hline
\end{tabular}

Note: Besides the coefficients shown, all specifications control for log of population and $\log$ of GDP and include firm fixed effects and a period fixed effect. For the coefficients shown in the table, variables are standardized as z-scores. 
Table 5: Robustness to alternative treatment of the "grey" and "other" categories

\begin{tabular}{lccc}
\hline \multirow{2}{*}{ VARIABLES } & \multicolumn{1}{c}{$(1)$} & $(2)$ & $(4)$ \\
Values & $0.175^{* * *}$ & $0.0590^{* *}$ & $0.188^{* * *}$ \\
& $(0.0283)$ & $(0.0245)$ & $(0.0205)$ \\
comp & -0.210 & $0.498^{* * *}$ & -0.210 \\
& $(0.182)$ & $(0.170)$ & $(0.140)$ \\
ValuesXCompetition & $0.0407^{* * *}$ & 0.00756 & $0.0177^{* *}$ \\
& $(0.0142)$ & $(0.0118)$ & $(0.00787)$ \\
Log fuel price & $0.413^{* *}$ & $0.645^{* * *}$ & -0.0456 \\
& $(0.196)$ & $(0.160)$ & $(0.164)$ \\
Clean & & & clean \\
Dirty & clean & clean + grey & dirty + grey + other \\
Observations & dirty + grey & dirty & 49,482 \\
R-squared & 17,124 & 17,124 & 0.051 \\
Number of firms & 0.070 & 0.149 & 24,741 \\
\hline
\end{tabular}


Table 6: Decomposition of historical changes

\begin{tabular}{|c|c|c|c|c|c|c|}
\hline $\begin{array}{c}\text { Change } \\
\text { relative } \\
\text { to } 1997-2002 \\
\text { (in percentage } \\
\text { points) }\end{array}$ & $\overline{\Delta \text { Total }}$ & $\begin{array}{l}\text { Due to } \\
\Delta \text { Social }\end{array}$ & $\begin{array}{l}\text { Due to } \\
\Delta \text { Comp }\end{array}$ & $\begin{array}{r}\text { Due to } \\
\Delta \text { Social \& } \\
\Delta \text { Comp }\end{array}$ & $\begin{array}{c}\text { Due to } \\
\Delta \text { Social \& } \\
\Delta \text { Comp \& } \\
\Delta \log \text { FuelPrice }\end{array}$ & $\begin{array}{r}\text { Due to } \\
\text { other factors } \\
\text { e }\end{array}$ \\
\hline Clean Share & 23.80 & 5.70 & 7.00 & 7.40 & 29.00 & -5.20 \\
\hline Dirty Share & -20.70 & -4.60 & -7.30 & -7.60 & -23.90 & 3.20 \\
\hline Grey Share & -3.20 & -1.20 & 0.20 & 0.00 & -5.20 & 2.00 \\
\hline
\end{tabular}

Notes: The table reports how much of the historic changes (comparing the 1997-2002 with the 2007-2012 period) in the shares of different technologies we can attribute to different factors according to our regressions reported in Table 1. Column 1 reports the actual change; e.g. the share of clean innovations increased by 23.8 percentage points (pcps). A change of 5.70 pcps would have happened if social attitudes only had changed between the two periods. Competition, social attitudes and fuel prices changes combined imply an increase of 29 pcps. As this is larger than the actual change we can infer that other factors must have had a dampening effect on clean innovation amounting to a reduction of 5.20 pcps of the clean share.

Table 7: Descriptive statistics for counterfactual exercises

\begin{tabular}{lcccc}
\hline \hline & mean & $\mathrm{p} 5$ & $\mathrm{p} 50$ & $\mathrm{p} 95$ \\
\hline$\Delta$ Social & -0.74 & -1.65 & -0.91 & 0.54 \\
$\Delta$ Competition & 0.86 & 0.55 & 0.91 & 0.94 \\
$\Delta$ logFuelPrice & 1.70 & 1.60 & 1.60 & 2.25 \\
\hline \hline
\end{tabular}


Table 8: Counterfactual exercise

\begin{tabular}{lrrr}
\hline \hline $\begin{array}{c}\text { Change relative } \\
\text { to 2007-2012 } \\
\text { (in percentage } \\
\text { points) }\end{array}$ & $\Delta$ Social $=0.74$ & Due to & $\begin{array}{r}\text { Due to } \\
\text { S }\end{array}$ \\
\hline Clean Share & & & $\begin{array}{r}\Delta \text { Comp }=0.86=0.86 \\
\text { Equivalent price growth in \% }\end{array}$ \\
\hline \hline
\end{tabular}

Notes: The table reports the effect of a uniform increasing in the social attitude and competition scores equivalent to the average absolute change we observed in those variables between the earlier and later sample period on the the share of clean innovation (Row 1). Row 2 shows the equivalent change in fuel prices triggering the same response. 


\section{Appendix A. Proofs of Proposition 2 and 3}

Proof or Proposition 2. For all $\kappa>\kappa_{1}$, so that $z$ is interior, we can write total emissions as:

$$
X(\Delta)=\left(1-\frac{\Delta \pi_{M}}{\kappa}\right)\left[1-2(1-\Delta) \pi_{M}\right]+\frac{\Delta}{\kappa \gamma} \pi_{M}\left(1-\pi_{M}\right) .
$$

Thus, $X(1)<X(1 / 2)$ if and only if:

$$
\begin{aligned}
1-\frac{\pi_{M}}{\kappa}+\frac{\pi_{M}\left(1-\pi_{M}\right)}{\kappa \gamma} & <\left(1-\frac{\pi_{M}}{2 \kappa}\right)\left(1-\pi_{M}\right)+\frac{\pi_{M}\left(1-\pi_{M}\right)}{2 \kappa \gamma} \Longleftrightarrow \\
\frac{\pi_{M}\left(1-\pi_{M}\right)}{2 \kappa \gamma} & <\left(1-\frac{\pi_{M}}{2 \kappa}\right)\left(1-\pi_{M}\right)-\left(1-\frac{\pi_{M}}{\kappa}\right)=\frac{\pi_{M}\left(1+\pi_{M}\right)}{2 \kappa}-\pi_{M} \Longleftrightarrow \\
\frac{1-\pi_{M}}{\gamma} & <1+\pi_{M}-2 \kappa,
\end{aligned}
$$

which is equivalent to (11). Let us next determine where $X$ achieves its maximum on $[1 / 2,1]$ :

$$
\kappa \frac{\partial X}{\partial \Delta}=-4 \pi_{M}^{2} \Delta+\left(2 \kappa-1+2 \pi_{M}\right) \pi_{M}+\frac{1}{\gamma} \pi_{M}\left(1-\pi_{M}\right)
$$

so $\partial X / \partial \Delta>0$ if and only if

$$
\Delta<\frac{1}{4 \pi_{M}}\left(2 \kappa-1+2 \pi_{M}+\frac{1-\pi_{M}}{\gamma}\right)=\frac{1}{2}+\frac{1}{4 \pi_{M}}\left(2 \kappa-1+\frac{\gamma^{-\delta}}{\gamma}\right) \equiv \hat{\Delta}_{X}(\kappa, \gamma, \delta) .
$$

Naturally, $\hat{\Delta}_{X}$ is increasing in $\kappa$ and decreasing in both $\gamma$ and $\delta$ (recall that $\pi_{M}=$ $\left.1-\gamma^{-\delta}\right)$. Moreover,

$$
\begin{aligned}
& \hat{\Delta}_{X}(\gamma, \delta)<\frac{1}{2} \Longleftrightarrow \kappa<\frac{1}{2}\left(1-\frac{\gamma^{-\delta}}{\gamma}\right)=\kappa_{2}-\frac{\pi_{M}}{2} \equiv \kappa_{3}, \\
& \hat{\Delta}_{X}(\gamma, \delta)>1 \Longleftrightarrow \kappa>\kappa_{3}+\pi_{M}=\kappa_{2}+\frac{\pi_{M}}{2} \equiv \kappa_{4}
\end{aligned}
$$

where $\kappa_{2}>\kappa_{1}=\pi_{M}$ was given in equation (11). It then follows that (under the maintained assumption that $\kappa>\kappa_{1}$, ensuring an interior optimum for $z$ ) :

(i) If $\kappa<\kappa_{2}-\kappa_{1} / 2, Z$ is decreasing in $\Delta$, and thus minimized at $\Delta=1$.

(ii) If $\kappa>\kappa_{2}+\kappa_{1} / 2$, then $Z$ is increasing in $\Delta$, and thus minimized at $\Delta=1 / 2$.

(iii) If $\kappa \in\left(\kappa_{2}-\kappa_{1} / 2, \kappa_{2}+\kappa_{1} / 2\right)$ then $X$ is hump-shaped in $\Delta$, with a maximum at $\hat{\Delta}_{Z}(\gamma, \delta) \in(1 / 2,1)$ and a minimum either at $1 / 2$ or at 1 , depending on $\kappa \gtrless \kappa_{2}$ (recall 
that this is what defines $\kappa_{2}$ ).

Note, finally, that conditions $\kappa>\pi_{M}$ and $\kappa<\kappa_{2}-\pi_{M} / 2$ define a nonempty interval when $3 \pi_{M}<2 \kappa_{2}$, that is, $\gamma^{-\delta}(2-1 / \gamma)>1$, or

$$
\delta<\ln (2-1 / \gamma) / \ln \gamma
$$

Proof or Proposition 3. From (15), when $\kappa>\kappa_{1}$, we have

$$
\kappa \frac{\partial X}{\partial \pi_{M}}=\frac{\Delta}{\kappa}\left[-1+2(1-\Delta) \pi_{M}+\frac{1-\pi_{M}}{\gamma}\right]-2(1-\Delta)\left(1-\frac{\Delta \pi_{M}}{\kappa}\right)-\frac{\Delta \pi_{M}}{\kappa \gamma} .
$$

The last two terms are clearly negative, and so is the first, since $\left(1-\pi_{M}\right) / \gamma<1-\pi_{M} \leq$ $1-2(1-\Delta) \pi_{M}$ for all $\Delta \geq 1 / 2$. Recalling that $\pi_{M}=1-\gamma^{-\delta}$, it follows that $\partial X / \partial \delta<0$. When $\kappa \leq \kappa_{1}$, R\&D effort may be (depending on $\Delta$ ) at a corner, $z=1$, in which case $X=y_{M} / \gamma=1 / c \gamma^{-\delta-1}$, which decreases in $\delta$.

Finally, differentiating 16 in $\pi_{M}$,

$$
\begin{aligned}
\kappa \frac{\partial^{2} X}{\partial \Delta \partial \pi_{M}} & =-4\left(1-2 \pi_{M}\right) \Delta+\frac{1}{\gamma}\left(1-2 \pi_{M}\right)-2 \kappa+2\left(1-2 \pi_{M}\right)-1 \\
& =\left(1-2 \pi_{M}\right)\left[\frac{1}{\gamma}+2-4 \Delta\right]-1-2 \kappa .
\end{aligned}
$$

If $1-2 \pi_{M} \geq 0$, the right-hand side is bounded above by $\left(1-2 \pi_{M}\right) / \gamma-1-2 \kappa<$ $1 / \gamma-1-2 \kappa<0$. If $1-2 \pi_{M}<0$, it is bounded above by $\left(2 \pi_{M}-1\right)(2-1 / \gamma)-1-2 \kappa$, since $\Delta \leq 1$; but $\pi_{M} \leq 1$, so this expression is at most $1-1 / \gamma-2 \kappa<0$, since $\kappa>\kappa_{1}=1-1 / \gamma^{\delta}>1-1 / \gamma$. Recalling that $\pi_{M}=1-\gamma^{-\delta}$, we therefore have $\partial^{2} X / \partial \Delta \partial \delta<0$ for all $\Delta$, as long as $\kappa>\kappa_{1}$.

Proof or Proposition 4. Part (a) follows directly from Proposition 2 and 3. For (b) recalling (3), (5) and (12), we have:

$$
\begin{aligned}
U & =\left(1-\frac{\Delta \pi_{M}}{\kappa}\right) \ln \left(1-2(1-\Delta) \pi_{M}\right)+\ln \left(\frac{1}{c}\right) \\
\frac{\partial U}{\partial \pi_{M}} & =\frac{\Delta}{\kappa} \ln \left(\frac{1}{1-2(1-\Delta) \pi_{M}}\right)-\frac{2(1-\Delta) \pi_{M}}{1-2(1-\Delta) \pi_{M}}\left(1-\frac{\Delta \pi_{M}}{\kappa}\right),
\end{aligned}
$$


It is clear that $\partial U / \partial \Delta>0$, while $\partial U / \partial \pi_{M}>0$ if and only if

$$
\kappa<\Delta\left[\pi_{M}+f\left(\frac{2(1-\Delta) \pi_{M}}{1-2(1-\Delta) \pi_{M}}\right)\right]
$$

where $f(t) \equiv \ln (1+t) / t$ for all $t>0$ and $f(0) \equiv \lim _{t \rightarrow 0} f(t)=1$. Note that $f$ is a decreasing function, since $f^{\prime}(t)$ has the sign of $g(t) \equiv t-(1+t) \ln (1+t)$, where clearly $g^{\prime}(t)<0=g(0)$ for all $t>0$. The right-hand side of (24) is thus increasing in $\Delta$, so the inequality holds if and only if $\Delta>\Delta\left(\pi_{M}, \kappa\right)$, with

$$
\begin{aligned}
& \underline{\Delta}\left(\pi_{M}, \kappa\right) \quad<\Longleftrightarrow \kappa<1+\pi_{M}, \\
& \underline{\Delta}\left(\pi_{M}, \kappa\right)<1 / 2 \Longleftrightarrow \kappa<\frac{1}{2}\left[\pi_{M}+f\left(\frac{\pi_{M}}{1-\pi_{M}}\right)\right] \equiv \bar{\kappa}\left(\pi_{M}\right),
\end{aligned}
$$

Condition (25) is always compatible with $\kappa>\pi_{M}$ and $\kappa<\kappa_{2}-\pi_{M} / 2$. Condition (26), which ensures that $\partial U / \partial \pi_{M}>0$ for all values of $\Delta \in[1 / 2,1]$, is more demanding since $\bar{\kappa}\left(\pi_{M}\right)<\left(1+\pi_{M}\right) / 2$ and compatible with $\kappa>\pi_{M}$, only if

$$
\pi_{M}<f\left(\frac{\pi_{M}}{1-\pi_{M}}\right)=\frac{\ln \left[1 /\left(1-\pi_{M}\right)\right]}{\pi_{M} /\left(1-\pi_{M}\right)} \Longleftrightarrow \pi_{M}^{2}<\left(1-\pi_{M}\right) \ln \left(\frac{1}{1-\pi_{M}}\right),
$$

which holds for instance when $\pi_{M}$ is small enough, meaning that $\delta \ln \gamma$ is small enough. This finishes to establish (b). Turning now to (c), we have

$$
\frac{\partial U}{\partial \Delta}=\frac{\pi_{M}}{\kappa} \ln \left(\frac{1}{1-2(1-\Delta) \pi_{M}}\right)+\left(1-\frac{\Delta \pi_{M}}{\kappa}\right) \frac{2 \pi_{M}}{1-2(1-\Delta) \pi_{M}}>0 .
$$

Moreover, the first term is increasing in $\pi_{M}$, and while the second not always is, a sufficient condition is that $\left(\Delta \pi_{M} / \kappa\right)\left(1-\Delta \pi_{M} / \kappa\right)$ be increasing, which occurs for $\Delta \pi_{M} / \kappa<1 / 2$; conversely, $\pi_{M} / \kappa<1 / 2$ is necessary the second term for that same term to be increasing in $\Delta$ up to $\Delta=1$. Thus, when $\kappa>2 \pi_{M}=2 \kappa_{1}$, we have $\partial^{2} U / \partial \Delta \partial \delta>0$.

We check, finally, that this new lower bound on $\kappa$ is compatible with key upper bounds previously defined, meaning that they jointly define a nonempty set of values for 
$(\kappa, \gamma, \delta)$. We have

$2 \pi_{M}<\kappa_{2}-\pi_{M} / 2 \Longleftrightarrow 5\left(1-\gamma^{-\delta}\right)<2 \kappa_{2}=2-\gamma^{-\delta}(1+1 / \gamma) \Longleftrightarrow \delta<\frac{\ln (4 / 3-1 / 3 \gamma) .}{\ln \gamma}$.

$2 \pi_{M}<\bar{\kappa}\left(\pi_{M}\right) \Longleftrightarrow 3 \pi_{M}<f\left(\frac{\pi_{M}}{1-\pi_{M}}\right)=\frac{\ln \left[1 /\left(1-\pi_{M}\right)\right]}{\pi_{M} /\left(1-\pi_{M}\right)} \Longleftrightarrow 3 \pi_{M}^{2}<\left(1-\pi_{M}\right) \ln \left(\frac{1}{1-\pi_{M}}(3 \phi)\right.$

The first condition is naturally tighter than $(20)$, so when it holds we have $\partial^{2} U / \partial \Delta \partial \delta>$ 0 for all $\Delta$ and $\partial U / \partial \delta>0$ for $\Delta$ in some nonempty interval $(\underline{\Delta}, 1]$. If the second condition also holds (which is ensured by some additional upper bound on $\delta$ ), then $\partial^{2} U / \partial \Delta \partial \delta>0>\partial U / \partial \delta>0$ for all $\Delta \in[1 / 2,1]$. 


\section{Appendix B. Computation of firm level Lerner Index}

We estimate firm level measures of competition using a (revenue) production function framework. Note that firm level (log) revenue $\left(R_{i t}\right)$ growth can be written as

$$
\Delta r_{i t} \approx \frac{\gamma}{\bar{\mu}_{i t}}+\bar{s}_{M i t}\left(\Delta m_{i t}-\Delta k_{i t}\right)+\bar{s}_{L i t}\left(\Delta l_{i t}-\Delta k_{i t}\right)+\frac{1}{\bar{\mu}_{i t}} \Delta \omega_{i t}
$$

where $\Delta r_{i t}=\ln R_{i t}-\ln R_{i t-1}$ (and equivalently for production factors) and we assume a homothetic translog production function with materials $M_{i t}$ and labor $L_{i t}$ as flexible factors and capital $K_{i t}$ a quasi fixed production factor. $\gamma$ is a scale paramter. $\bar{s}_{M i t}=$ $\frac{s_{M i t}+s_{M i t-1}}{2}$ is the average share of materials expendisture in revenue between period $t$ and $t-1$ (and equivalently for labor inputs). $\omega$ is a composite shock comprising of a Hicks neutral production shifter (TFPQ) and a demand shifter. $\bar{\mu}_{i t}$ is the average markup of prices over marginal cost between period $t$ and $t-1$. Hence, $\bar{\mu}_{i t}-1$ is a Lerner index specific to firm $i$ at time $t$. Short run profit maxmisation implies that

$$
s_{M i t}=\frac{\alpha_{M i t}}{\mu_{i t}}
$$

where $\alpha_{\text {Mit }}$ is the elasticity of output w.r.t to changes in production factor $M$ (and analougously for labor). Note that in the translog case

$$
\alpha_{M i t}=\alpha_{M}+\alpha_{K M} k_{i t}+\alpha_{L M} l_{i t}+\alpha_{M M} m_{i t}
$$

Note that the specification is consistent with a wide variaty of market structures. For further discussion see Martin (2012) and Forlani (2016). We can rewrite equation 31 as

$$
L H S_{i t} \frac{\bar{\alpha}_{M i t}}{\gamma}-\Delta k_{i t}=\frac{1}{\gamma} \Delta \omega_{i t}
$$

where

$$
L H S_{i t}=\frac{\Delta r_{i t}-\frac{\gamma}{\bar{\mu}_{i t}}+\bar{s}_{M i t}\left(\Delta m_{i t}-\Delta k_{i t}\right)+\bar{s}_{L i t}\left(\Delta l_{i t}-\Delta k_{i t}\right)}{\bar{s}_{M i t}}
$$

Subject to assumptions about the evolution of the $\Delta \omega_{i t}$ shock, we can fit this to standard firm level data using a GMM approach; e.g. suppose that $\Delta \omega_{i t}$ follows an $\operatorname{AR}(1)$ process so that 


$$
\omega_{i t}=\rho \omega_{i t-1}+\eta_{i t}
$$

where $\eta_{i t} \sim$ iid. We can then write

$$
\hat{\eta}_{i t}=L H S_{i t} \frac{\bar{\alpha}_{M i t}}{\gamma}-\Delta k_{i t}-\frac{\rho}{\gamma}\left[L H S_{i t-1} \frac{\bar{\alpha}_{M i t-1}}{\gamma}-\Delta k_{i t-1}\right]
$$

and to estimate the parameters

$$
\delta=\left[\frac{\rho}{\gamma}, \frac{\alpha_{M}}{\gamma}, \frac{\alpha_{K M}}{\gamma}, \frac{\alpha_{L M}}{\gamma}, \frac{\alpha_{M M}}{\gamma}\right]
$$

we can use the moment conditions

$$
E\left\{\hat{\eta}_{i t} \times\left[L H S_{i t-1}, \frac{1}{\Delta k_{i t}}, \frac{\bar{k}_{i t}}{\Delta k_{i t}}, \frac{\bar{l}_{i t}}{\Delta k_{i t}}, \frac{\bar{m}_{i t}}{\Delta k_{i t}}\right]\right\}
$$

After identifying $\delta$, we can compute $\frac{\widehat{\alpha_{\text {Mit }}}}{\gamma}$ using equation 33 Using 32 we can then compute

$$
\frac{\widehat{\gamma}}{\mu_{i t}}=s_{M i t}\left(\frac{\widehat{\alpha_{M i t}}}{\gamma}\right)^{-1}
$$

which is an inverse Lerner Index scaled by the returns to scale parameter $\gamma$; i.e. it tells us the excess of markups over returns to scale. Hence, while this is different from the markup over marginal costs this is the more relevant in terms of measuring market power as it corresponds to the excess earnings over what would be reasonable to compensate for increasing returns.

We also implement a simpler version assuming a Cobb Douglas production function implying that $\alpha_{M i t}=\alpha_{M}$. Both approaches lead to similar results.

\section{Appendix C. Calculation of counterfactuals}

We can write our regression model as

$$
\log \left(P A T_{j t}+1\right)=X_{j t} b+\varepsilon_{j t}
$$

where $P A T_{j t}$ is the number of patents (or patent families) of firm $j$ at time $t, X_{j t}$ is a vector collecting all explanatory variables and $b$ is a vector of coefficients. For simplicity we abstract from different technology types. For an observed level of $P A T_{j t}$ 
and $X_{j t}$ and $\hat{b}$ an estimate of $b$, we can compute the counterfactual level of innovation $P A T_{j t}^{C F}$ in response to a counterfactual change in the explanatory variables $\Delta X_{j t}^{C F}$, We can express the counterfactual level of innovation for a given counterfactual change in $\Delta X_{j t}^{C F}$ relative to an actual level $X_{j t}$ as

$$
P A T_{j t}^{C F}=\left(P A T_{j t}+1\right) \times \exp \left(\Delta X_{j t}^{C F} \hat{b}\right)-1
$$

Hence, for all counterfactual scenarios reported in section XX we compute the counterfactual levels at the firm level and then aggregate over all firms to produce the results reported above. 


\section{Appendix Tables}

Table A1: Patent CPC classification codes used

\begin{tabular}{ll}
\hline & \multicolumn{1}{c}{ Clean } \\
Y02T10/60 & Other road transportation technologies with climate change mitigation effect \\
Y02T10/70 & Energy storage for electromobility \\
Y02T90/10 & Technologies related to electric vehicle charging \\
Y02T90/34 & Fuel cell powered electric vehicles \\
Y02T90/42 & Hydrogen as fuel for road transportation \\
\hline & \multicolumn{1}{c}{ Grey } \\
Y02T10/10 & Climate change mitigation technologies related to fuel injection \\
Y02T10/20 & Climate change mitigation technologies related to exhaust after treatment \\
Y02T10/40 & Climate change mitigation technologies related to engine Management Systems \\
Y02T10/50 & Climate change mitigation technologies related to Intelligent Control Systems \\
\hline & Combustion Engines \\
F02 & Dirty \\
\hline & Oehicles in General
\end{tabular}

Notes: The table reports the Cooperative Patent Classification (CPC) classification used to determine the different flavours of innovation.

https://www.cooperativepatentclassification.org/index 